\title{
Scanning electron microscopy and rock magnetic studies of magnetic carriers in remagnetized early Paleozoic carbonates from Missouri
}

\author{
Weiwei Sun and Mike Jackson \\ Institute for Rock Magnetism and Department of Geology and Geophysics, University of Minnesota, Minneapolis
}

\begin{abstract}
Magnetic carriers in remagnetized early Paleozoic carbonates of the North American midcontinent were studied in extracts and in situ, using rock magnetism and scanning electron microscopy (SEM). SEM observation of extracts and in situ samples shows that the dominant magnetic particles are large irregular grains and framboids (10-20 $\mu \mathrm{m}$ in diameter) and individual spherical and euhedral particles $(0.2-1 \mu \mathrm{m})$. Comparing the saturation remanence of the bulk rock and extracts indicates that the extracts only account for $\sim 10 \%$ of the saturation remanence of the bulk rock. Most of the remanence carriers were lost during the dissolution and separation procedure, especially the finer-grained carriers. The framboids and the individual submicron euhedral magnetic particles observed by SEM thus make a fairly minor contribution to the magnetic remanence of the remagnetized carbonates. Hysteresis loops of the extracts are very similar to those reported by Suk et al (1993), with saturation remanence to saturation magnetization $\left(\mathrm{J}_{\mathrm{r}} / \mathrm{J}_{\mathrm{S}}\right)$ ratios from 0.1 to 0.13 and remanent to bulk coercivity $\left(\mathrm{H}_{\mathrm{Cr}} / \mathrm{H}_{\mathrm{C}}\right)$ ratios $\sim 4$. However, the loops for the "nonmagnetic" residue are strongly "wasp-waisted", and $\mathrm{H}_{\mathrm{cr}} / \mathrm{H}_{\mathrm{C}}$ ratios are very high, similar to whole rock specimens of remagnetized carbonates (Jackson, 1990). This suggests that bulk rock and "nonmagnetic" residue contain very fine (superparamagnetic (SP) and single domain (SD)) magnetic particles which were not recovered by the magnetic separation procedure. Low-temperature experiments support the conclusion that the principal remanence carriers in the remagnetized carbonates are SD magnetite and that SP magnetite plays an important part in the unusual bulk magnetic properties of these rocks. Owing to their dissolution, the actual natural remanent magnetization bearing particles cannot be observed petrographically.
\end{abstract}

\section{Introduction}

Extensive remagnetization in the midcontinent of North America during late Paleozoic time has been well recognized in recent years [e.g., McCabe and Elmore, 1989; Van der Voo, 1990]. Abundant evidence favors a chemical mechanism for the remagnetization, involving growth of diagenetic or authigenic magnetite. Scanning electron microscopy (SEM) observations of magnetic separates and thin sections have played a key role in documenting the occurrence of diagenetic magnetite [McCabe et al., 1983; Suk et al., 1990a, b, 1993; Lu et al., 1990, 1991]. Recently, attention has also focused on the magnetic properties of the remanence carriers [Jackson. 1990; Jackson et al., 1992, 1993; Suk and Halgedahl, 1992; Halgedahl and Suk, 1992; Suk et al., 1993] and on geochemical models of diagenetic magnetite formation [ $\mathrm{Lu}$ et al., 1991].

Although petrographic and rock magnetic observations each appear to favor a low-temperature chemical origin for the remanence carriers, there remain significant questions about where the remanence actually resides. SEM and transmission electron microscopy (TEM) studies [McCabe et al., 1983; Suk

Copyright 1994 by the American Geophysical Union.

Paper number 93JB02761.

0148-0227/94/93JB-02761\$05.00 et al., 1990a, b, 1993; Lu et al., 1990] have cataloged magnetite particles with a variety of morphologies and a range of grain sizes extending from submicron to several hundred microns. Framboidal and spheroidal grains with sizes of a few microns and larger, with pure $\mathrm{Fe}_{3} \mathrm{O}_{4}$ composition, have been found in extracts from many midcontinent localities [ $\mathrm{McC}$ abe et al., 1983; Bachtadse et al., 1987; Lu et al., 1990]. Textural relationships observed in situ between authigenic K-feldspar and nonspherical magnetite (up to $50 \mu \mathrm{m}$ ) led Suk et al. [1990a] to conclude that the two minerals are cogenetic. Thin section observations have also documented replacement of framboids and individual crystals of pyrite by magnetite [Suk et al., 1990b, 1993]. These petrographic observations have provided strong evidence that the magnetite has a diagenetic/authigenic origin.

However, the link between the observed diagenetic magnetite and the natural remanent magnetization (NRM) of the rocks is still unclear. Hysteresis measurements on whole rock samples of the Knox, Trenton, and Onondaga carbonate [Jackson, 1990] have pointed to dominantly fine-grained remanence carriers, which lack shape anisotropy and are consistent with an authigenic morphology (e.g., spherical or euhedral). Ratios of $\mathrm{J}_{\mathrm{rs}} / \mathrm{J}_{\mathrm{s}}$ that average about 0.25 and reach as high as 0.5 indicate that the ferromagnetic fraction cannot contain very much true multidomain (MD) material (for which $\mathrm{J}_{\mathrm{TS}} / \mathrm{J}_{\mathrm{S}} \leq 0.05$ [Day et al., 1977]). Thus most of $\mathrm{J}_{\mathrm{rs}}$ is carried by fine singledomain (SD) or pseudo-single-domain (PSD) magnetite particles that may not be observed in extracts or in situ SEM. 
Suk et al. [1993] have recently reported that equant, 200-nm single-crystal particles are common in remagnetized samples from New York State and that they exhibit PSD hysteresis behavior. They suggested that such particles may be important NRM carriers. Jackson et al. [1992, 1993] and Sun et al. [1993] have reported that remagnetized midcontinent localities have relatively high values of anhysteretic remanent magnetization (ARM) and saturation isothermal remanent magnetization (SIRM), a high ratio of ARM/SIRM, strong frequency dependence of susceptibility, and low ARM anisotropy. This evidence strongly indicates very fine magnetic grain sizes (SP and SD) and is consistent with authigenic morphology.

In order to understand the carriers of NRM in the carbonates, it is important to know how closely the extracts represent the magnetic carriers in the bulk rock. In this study we compare the rock magnetic properties of bulk rock, extracts, and "nonmagnetic" residues and conduct SEM observation of both extracts and in situ samples. These new magnetic studies allow us to document the extent to which magnetic carriers were lost during dissolution and extraction and how the separation process impacts the size distribution. Our SEM observations illustrate the mineralogical composition, morphology, and relationship in the in situ samples, extracts, and "nonmagnetic" residues.

\section{Methods}

The carbonate samples were collected from lower Ordovician strata near Springfield, Missouri. Previous study has shown that these samples were strongly remagnetized during late Paleozoic time [Jackson et al., 1992, Sun et al., 1993]. In order to examine the magnetic properties of extracts, the rock was first pulverized and then put in a $1 \mathrm{~N}$ acetic acid solution buffered with sodium acetate to a $\mathrm{pH}$ of 5 [see Lu et al., 1990]. The reagent was changed every day for approximately 6 weeks. Then the magnetic fraction was extracted using a high-gradient magnetic separation technique [Schulze and Dixon, 1979]. A drop tube with steel wool inside was placed between a pair of permanent magnets, and the slurry flowed through the tube at low velocity. This process was repeated several times to obtain maximum separation.

Hysteresis properties of the samples were measured on a vibrating sample magnetometer (VSM) and an alternating gradient force magnetometer (AGFM). Whole core samples ( $11 \mathrm{~cm}^{3}$ ) were measured on the VSM, while several chips of undissolved rock (less than $100 \mathrm{mg}$ ), the magnetic extracts (a few milligrams), and the residue (several tens of milligrams) were measured on the AGFM. Low-temperature measurements of bulk rock, separates, and "nonmagnetic" residue were performed on a quantum design magnetic property measurement system. Samples were saturated at $2 \mathrm{~K}$ and allowed to warm to room temperature in zero field, while the low-temperature remanence was measured at $5 \mathrm{~K}$ intervals. Also, a number of core samples in different magnetic states (NRM, ARM, SIRM) were cooled below the Verwey transition point (in a liquid nitrogen bath) and warmed up to room temperature in zero field.

SEM observations were made using a JEOL-840II installed with an energy dispersive spectrometer (EDS). All the SEM samples were carbon-coated for EDS analysis. A thin section polished with $0.1-\mu \mathrm{m}$ alumina powder was used for in situ SEM observation in order to observe the mineralogical or textural relationships. Magnetic separates and "nonmagnetic" residue were also observed with the SEM in order to try to identify possible remanence carriers.

\section{Results}

\section{Paleomagnetism}

Alternating field (AF) and thermal demagnetization indicate the presence of two components of NRM (Figure 1). The first is removed by fairly low-temperature $\left(<200^{\circ} \mathrm{C}\right)$ or AF $(<20 \mathrm{mT})$ demagnetization and has a steeply downward orientation. This component is interpreted as a Cenozoic viscous remanent magnetization. The stable component survives heating to approximately $500^{\circ} \mathrm{C}$ or AFs up to $80-100 \mathrm{mT}$, and has a SSE and shallow orientation. This behavior is very typical of remagnetized magnetite-bearing carbonates [McCabe and Elmore, 1989], and we conclude that these samples were entirely remagnetized during the Kiaman reverse polarity superchron in Permian time.

\section{SEM Observation}

Magnetic extracts and in situ samples examined under the SEM contain a variety of iron-bearing particles similar to magnetites described by previous investigators [e.g., $\mathrm{McC}$ abe et al., 1983; Lu et al., 1990; Suk et al., 1990a; Saffer and $M c C a b e, 1992]$. In the absence of $\mathrm{X}$ ray or TEM diffraction measurements, it is not possible to make a positive mineralogical identification of the individual particles; however, in view of the rock magnetic properties (indicating predominantly magnetite), it is probable that many of the particles observed consist of magnetite.

Extracts. Magnetic extracts from the undissolved residue are shown in Figure 2. Several kinds of magnetic particle are recognized under SEM observation. Many framboids composed of small euhedral particles (about $1 \mu \mathrm{m}$ ) are found in the extract (Figure 2a). These framboids usually are $\sim 10 \mu \mathrm{m}$ in diameter, and EDS component examination shows only iron, which suggests that the framboids are composed of iron oxides. This observation parallels those of previous studies [McCabe et al., 1983; Lu et al., 1990; Suk et al., 1990a; Saffer and McCabe,

$12-2 \mathrm{Al}$

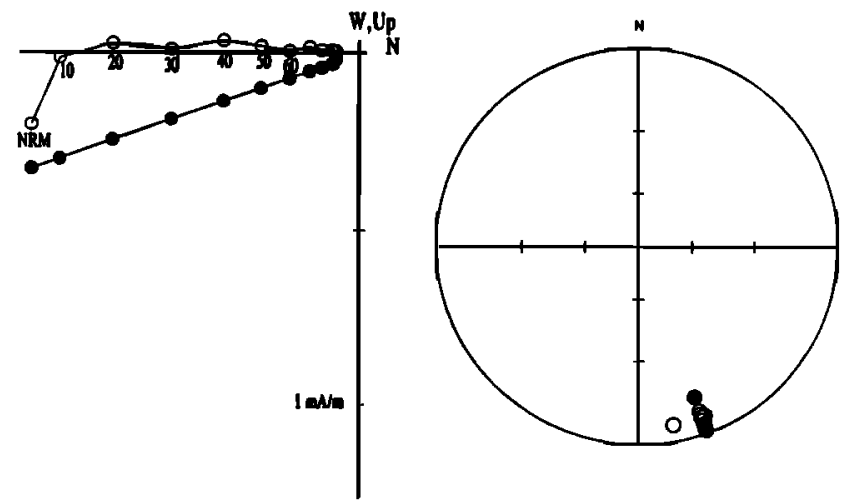

Figure 1. (left) Alternating field demagnetization vector plot and (right) stereo plot for a remagnetized sample. On the vector plot, open circles represent projections on the vertical plane, solid circles represent projections on the horizontal plane. On the stereo plot, solid circles represent positive inclination, open circles represent negative inclination. 


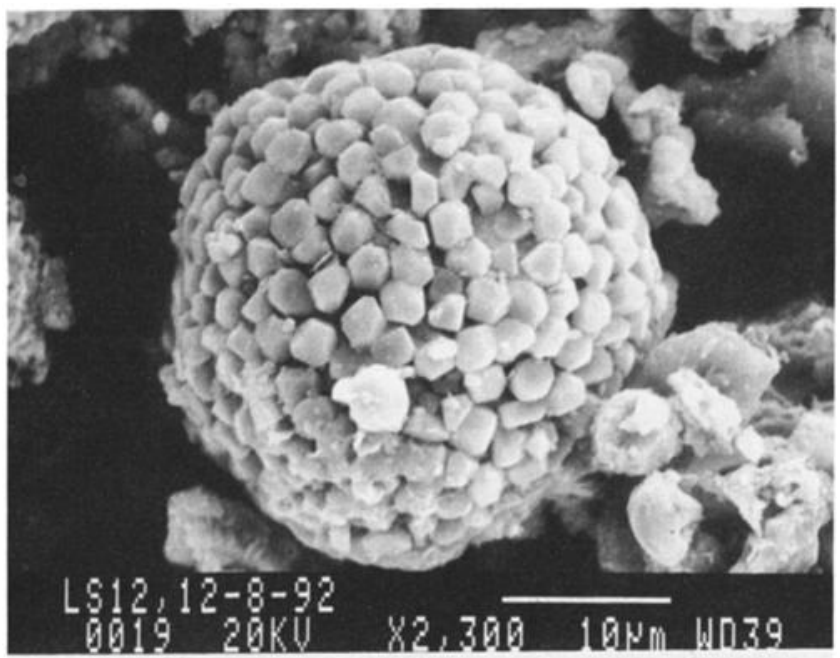

(a)

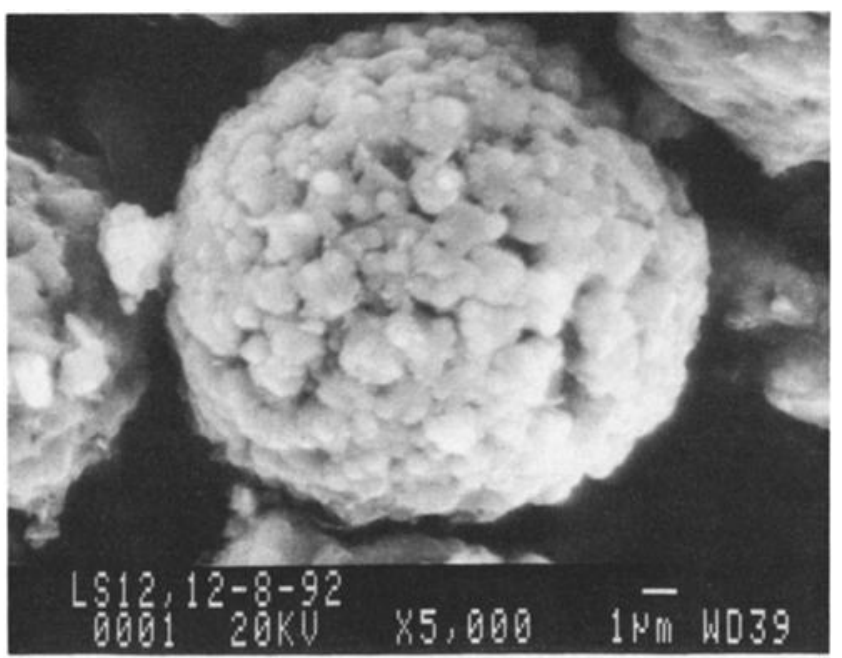

(b)

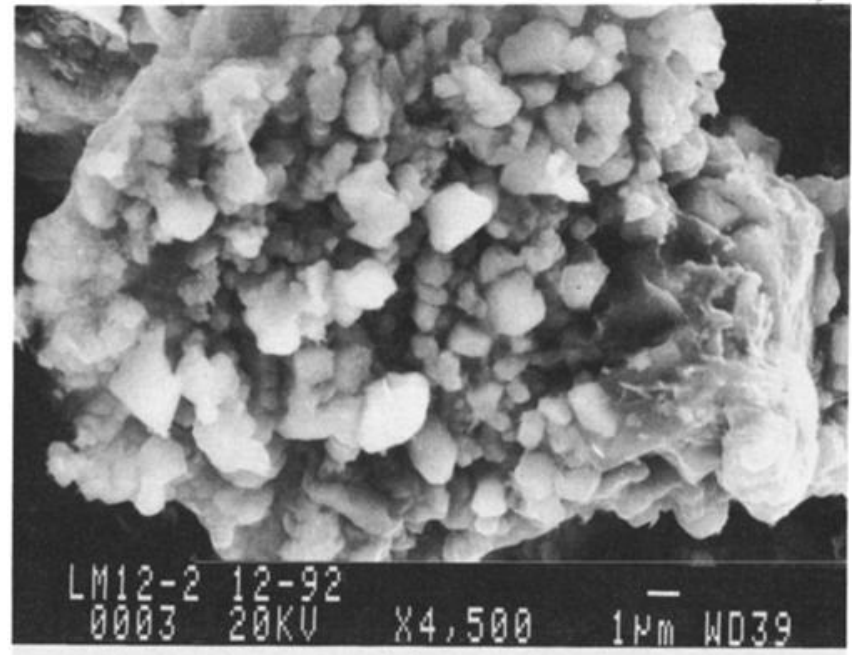

(c)

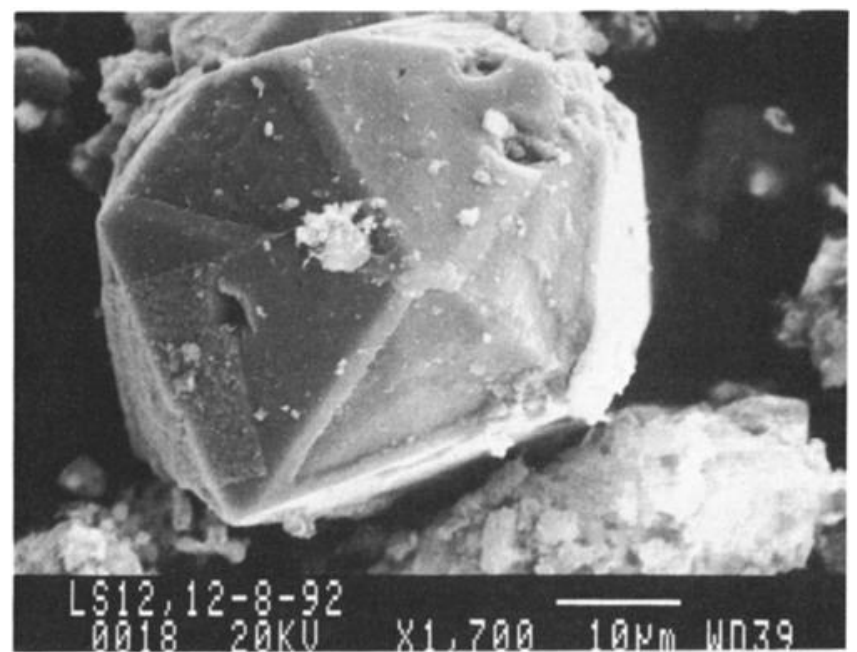

(d)

Figure 2. Scanning electron microscopy images of the extracts (a) Framboid composed of small (1-2 $\mu \mathrm{m})$ euhedral magnetic particles; (b) many small spherules $(0.2-0.5 \mu \mathrm{m}$ ) attached to a framboid surface; (c) aggregate composed of small euhedral magnetic particles (0.2-2 $\mu \mathrm{m})$; and (d) a large euhedral magnetic particle.

1992], which demonstrated that many of the framboids were composed of magnetite. Figure $2 \mathrm{~b}$ shows another framboid composed of euhedral particles. It appears somewhat different because there are many small spherules attached to its surface. These small spherules range from 0.2 to $0.5 \mu \mathrm{m}$. Particles smaller than $0.2 \mu \mathrm{m}$ cannot be seen because of the resolution of SEM. All these small spherules only contain iron according to EDS examination. The small spherules are also stuck to other minerals. In addition to the framboids, there are many aggregates composed of euhedral or semieuhedral particles which range from 0.2 to $1.5 \mu \mathrm{m}$ (Figure 2c). EDS shows a dominant iron peak with small silicon and potassium peaks in the aggregate (Figure 5a). Larger magnetic particles (from 2 to $30 \mu \mathrm{m})$ usually have an irregular shape, although some large euhedral magnetic particles can also be seen (Figure 2d). These large euhedral particles have very clear faces and edges, and they mostly contain iron without sulphur.

In situ observations. There are two kinds of magnetic particles observed in the in situ SEM observations. One is relatively large and irregular, and the other is framboidal. The irregular grains (Figure 3a) usually range from 20 to $30 \mu \mathrm{m}$. These irregular particles can often be found inside calcite or within a void. Some contain inclusions which are usually calcium or potassium feldspar. Figure $3 \mathrm{a}$ shows an irregular magnetic grain within a void in the carbonates. This grain has a bright core; the bright core and the dark rim only contain Fe. The dark rim may be due to the oxidation along the cracks [Furuta et al., 1985]. The carbonate void was also filled with irregular small grains (less than $3 \mu \mathrm{m}$ ) which contain only $\mathrm{Al}$, $\mathrm{K}$, and Si peaks (see Figure 5b). According to the distribution, grain size, shape, and EDS spectra of the irregular small grains, it appears likely that they are authigenic potassium feldspar, genetically related to late Pennsylvanian to early Permian potassium-rich brines [Hearn et al., 1989; Lu et al., 1991]. Similar K-feldspar grains also occur as inclusions in the irregular magnetic particles, as observed by Suk et al [1990a]; however, the boundary between the inclusions and magnetic particles is not clear. This indicates that some large 


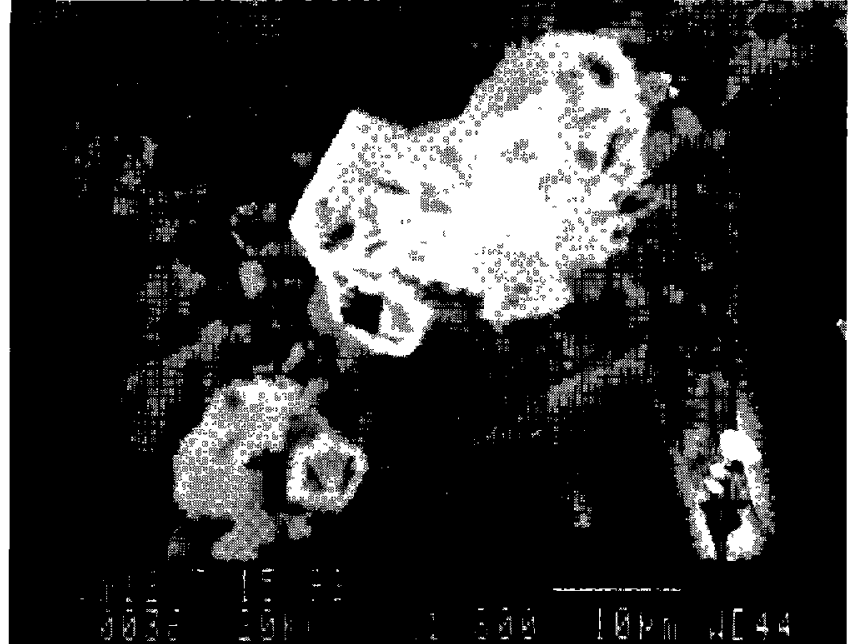

(a)

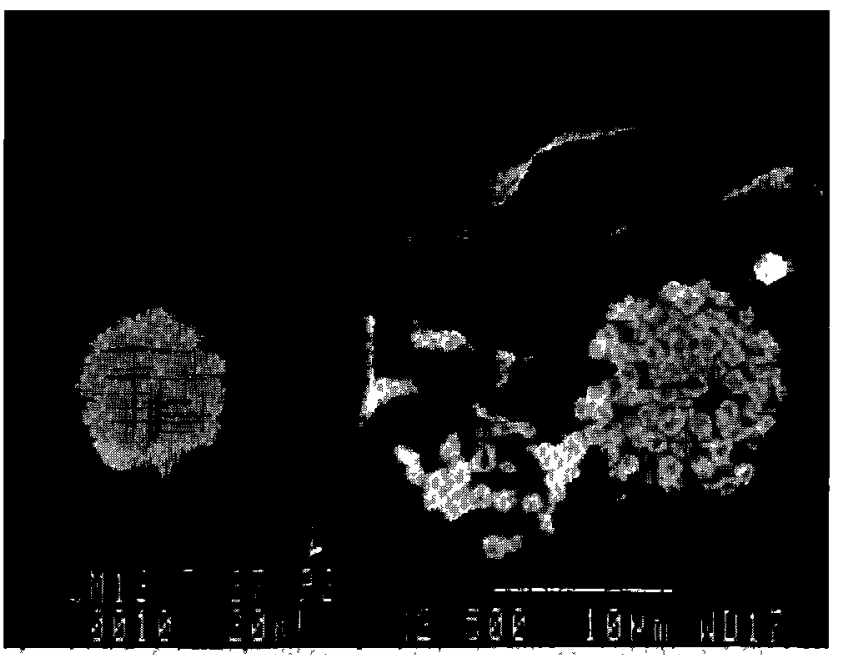

(b)

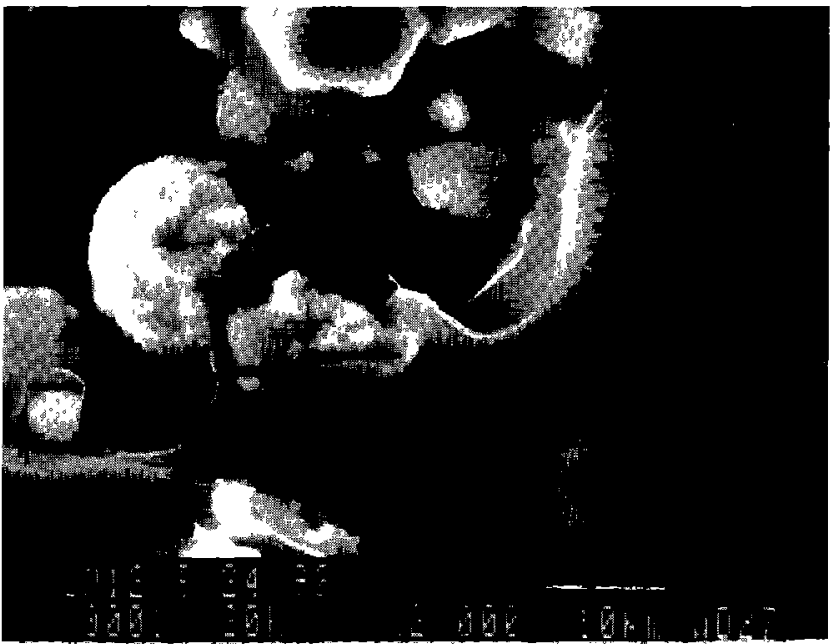

(c)

Figure 3. In situ SEM images (a) An irregular magnetic particle with oxidation rim in a void filled with K-feldspar. The inclusions inside the magnetic grain are also K-feldspar. (b) Framboids in a void and inside calcite. Framboid is composed of many individual octahedral magnetic grains. (c) A void containing framboids, individual euhedral magnetic grains, and secondary quartz. magnetic particles and the K-feldspar are cogenetic. Obviously, the oxidation rim occurred after the magnetic particle formation.

Many framboids are observed in situ (Figure 3b). The framboids, $\sim 10 \mu \mathrm{m}$ in diameter, most often occur in voids of calcite. Some framboids are clearly composed of individual octahedral grains (about $1 \mu \mathrm{m}$ ) which are shown by EDS examination to contain only Fe. These tiny octahedral grains usually have a bright rim; the center appears hollow. Both rim and center have only Fe peaks on the EDS spectrum. Some framboids are composed of fine powders, instead of tiny octahedral grains (Figure 3c). Some framboids and individual crystals coexist in voids with secondary euhedral quartz (Figure 3c). This again indicates a cogenetic origin. Most framboids occur in voids with few or no K-feldspar particles. Conversely, the voids filled with $\mathrm{K}$-feldspar do not contain framboids. This relationship suggests that pyrite framboids reacted with tectonic brine and induced no $\mathrm{K}$-feldspar deposition around the framboids. The few framboids contained in calcite indicate that they were not precipitated by the reaction of brine and Fe-rich clay; instead, they have a diagenetic origin.

The "nonmagnetic" residues are composed of large quartz and $\mathrm{K}$-feldspar particles ( 10-30 $\mu \mathrm{m})$, and small K-feldspar particles (less than $3 \mu \mathrm{m}$ ) (Figure 4). The residues mainly contain $\mathrm{Al}, \mathrm{Si}, \mathrm{K}$, and very little $\mathrm{Fe}$ (Figure $5 \mathrm{c}$ ). The tiny $\mathrm{Fe}$ peak may be due to SP particles remaining in the residues or to iron in the mineral composition.

\section{Rock Magnetism}

A total of $600 \mathrm{~g}$ of pulverized carbonate was placed in two beakers for dissolution. About $13 \mathrm{~g}$ insoluble residue (4.3\%) remained in each beaker after dissolution. Using high-gradient magnetic separation, $19.26 \mathrm{mg}$ and $23.99 \mathrm{mg}$, respectively, of magnetic extracts were recovered from the insoluble residues.

Hysteresis measurements were then made on the magnetic extracts and "nonmagnetic" residue for comparison with bulk rock behavior. All loops were processed to remove the paramagnetic or diamagnetic signal. The hysteresis loops of the bulk rock, magnetic extract, and residue are shown in Figure 6. The $J_{Y} / J_{S}$ ratio of the bulk rock samples is $\sim 0.3$ 0.35 , and $\mathrm{H}_{\mathrm{cr}} / \mathrm{H}_{\mathrm{c}}$ ranges from 2 to 3 . For the magnetic extracts, $\mathrm{J}_{\mathrm{r}} / \mathrm{J}_{\mathrm{S}}$ ratios are from 0.1 to 0.13 , and $\mathrm{H}_{\mathrm{cr}} / \mathrm{H}_{\mathrm{c}}$ is $\sim 4$. The hysteresis ratios for the extracts are very close to those

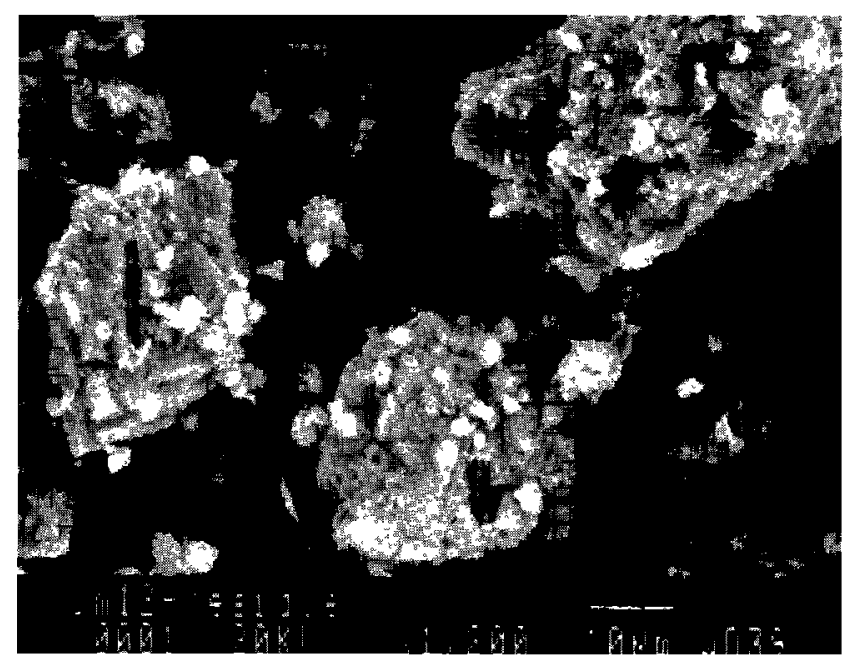

Figure 4. SEM images of "nonmagnetic" residue. 
(a)

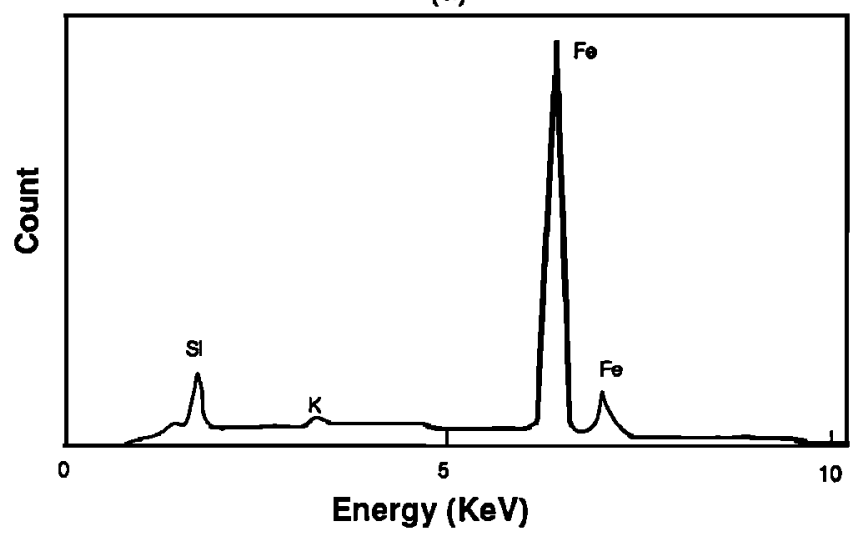

(b)

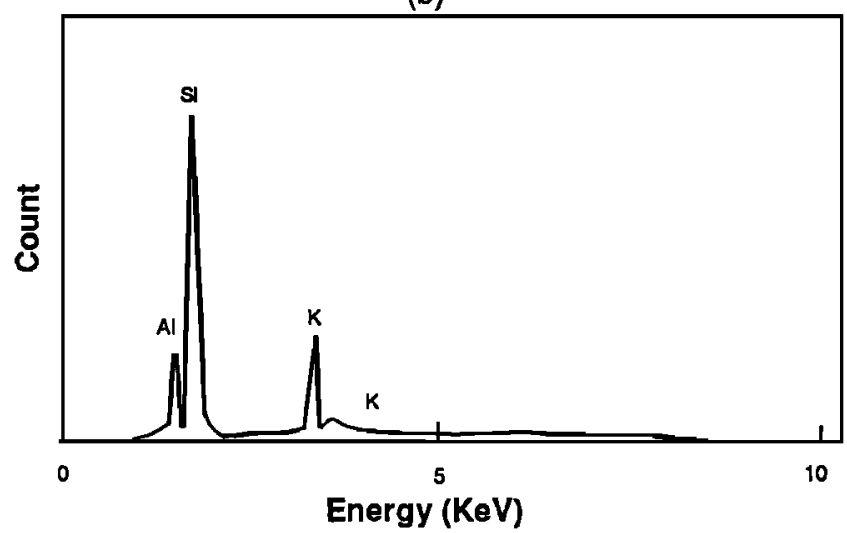

(c)

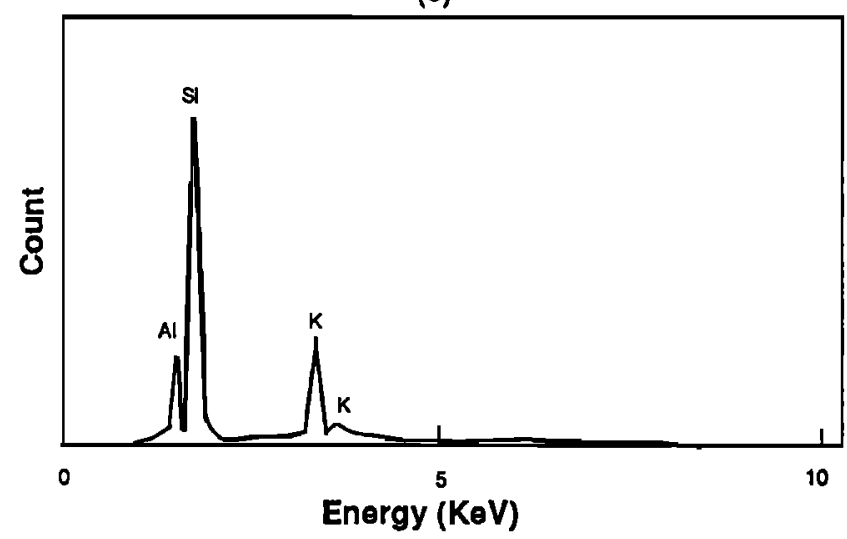

Figure 5. (a). Energy dispersive spectrometer (EDS) spectrum of small euhedral particles in the aggregate of Figure 2c. (b). EDS spectrum of the K-feldspar in the void in Figure 3a. (c). EDS spectrum of the "nonmagnetic" residues in Figure 4.

reported by Suk et al. [1993] for fine individual magnetite grains extracted from remagnetized carbonates from New York. The "nonmagnetic" residue has a $\mathrm{J}_{\mathrm{T}} / \mathrm{J}_{\mathrm{S}}$ ratio between 0.2 and 0.3 , and a large $\mathrm{H}_{\mathrm{cr}} / \mathrm{H}_{\mathrm{c}}$ ratio range from 7 to 12 . The loops were strongly "wasp-waisted" (Figure 6c), resembling loops of whole rocks from the Trenton, Onondaga, and Knox samples [Jackson, 1990]. Figure 7 shows a plot of the hysteresis ratios for bulk rock samples, magnetic extracts, and "nonmagnetic" residue in the framework of Day et al. [1977]. The bulk rock ratios are located in the PSD region, while for extracts, the ratios plot closer to the boundary between PSD and MD, and (a)

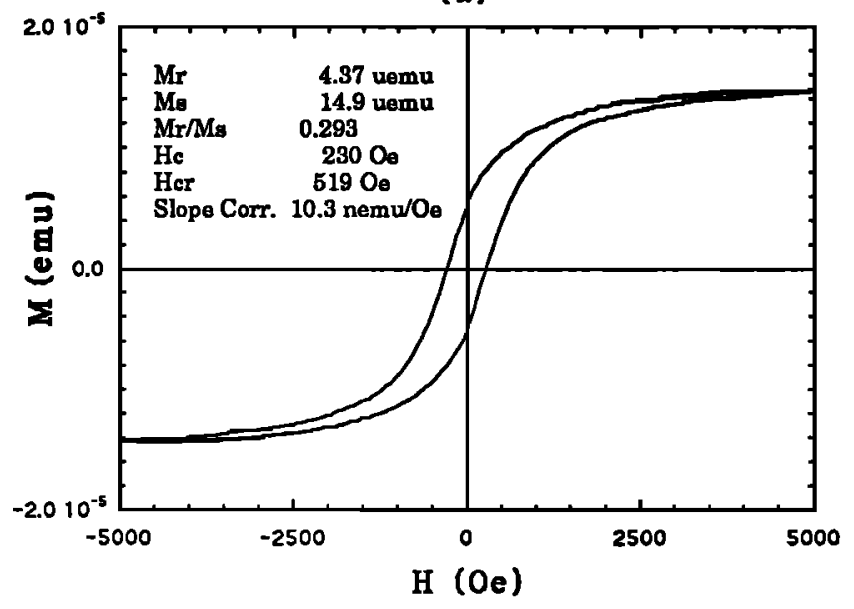

(b)

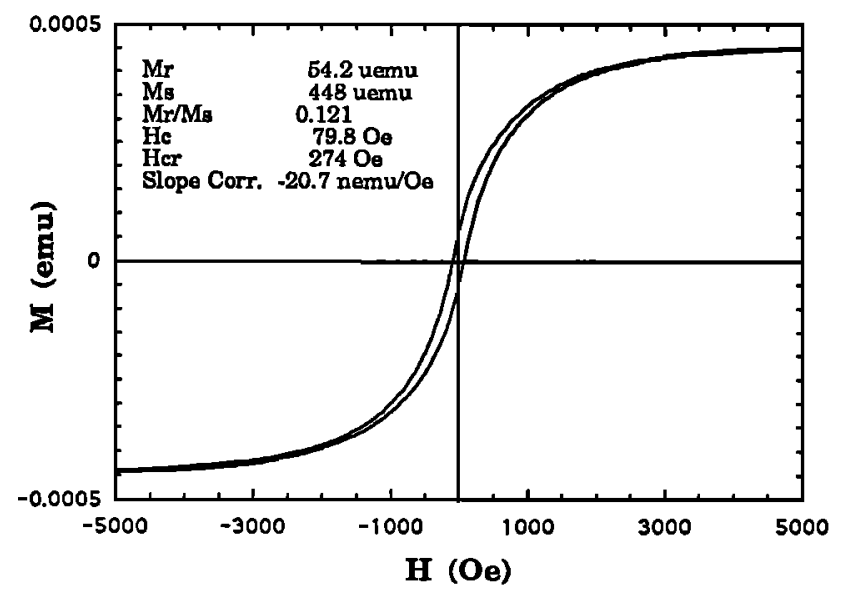

(c)

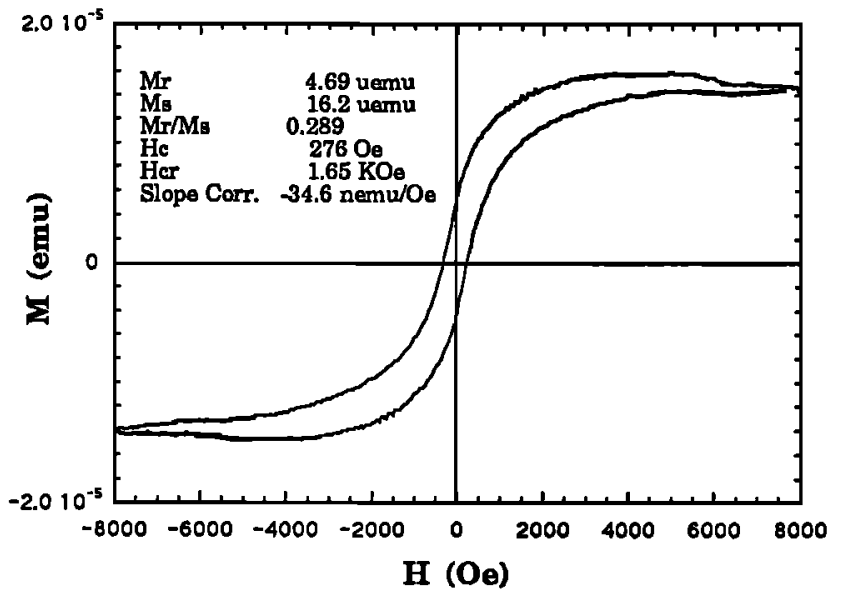

Flgure 6. Hysteresis loops of (a) bulk rock , (b) extracts, and (c) "nonmagnetic" residue.

the "nonmagnetic" residue has a higher ratio of $\mathrm{H}_{\mathrm{cr}} / \mathrm{H}_{\mathrm{c}}$. Table 1 shows the relationship between the moment of bulk rock, magnetic extract, and "nonmagnetic" residue. The magnetic extracts only account for $-20 \%$ of the original bulk rock's saturation moment $\left(M_{S}\right)$; roughly $15-20 \%$ of bulk rock's $M_{S}$ was left in the "nonmagnetic" residue. Approximately $60 \%$ of the bulk rock's saturation moment was lost during dissolution. Similarly, the extracts account for less than $10 \%$ of the bulk 


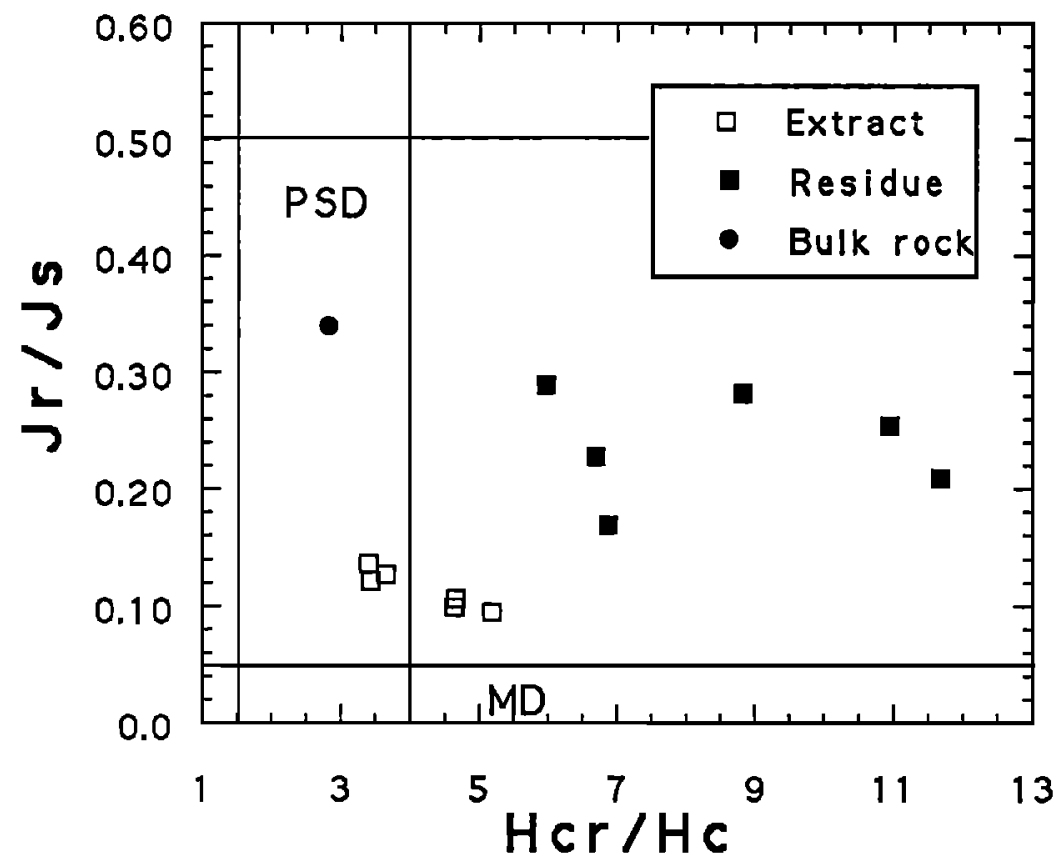

Figure 7. Summary plot of measured hysteresis ratios. The ratio for bulk rock is located in the pseudo single domain (PSD) region. Extract ratios are located near the boundary between PSD and multidomain.

Table 1. Magnetic Moment Comparison Between Bulk Rock, Magnetic Extracts and Nonmagnetic Residues

\begin{tabular}{|c|c|c|c|c|c|c|}
\hline & Mass (g) & $M_{s}\left(\mathrm{Am}^{2}\right)$ & $\mathrm{Mr}\left(\mathrm{Am}^{2}\right)$ & $\mathrm{M}_{\mathbf{S}} / \mathrm{M}_{\mathbf{S}}$ Bulk & $\mathrm{M}_{\mathrm{I}} / \mathrm{M}_{\mathrm{I}}$ Bulk & $\mathrm{M}_{\mathrm{r}} / \mathrm{M}_{\mathrm{S}}$ \\
\hline \multicolumn{7}{|l|}{ Sample 12-1 } \\
\hline Bulk rock & 300 & $4.07 \times 10^{-5}$ & $1.38 \times 10^{-5}$ & 1 & 1 & 0.34 \\
\hline Extracts & 0.01926 & $8.147 \times 10^{-6}$ & $1.03 \times 10^{-6}$ & 0.2 & 0.075 & 0.127 \\
\hline Residues & 12.59 & $9.98 \times 10^{-6}$ & $2.3 \times 10^{-6}$ & 0.24 & 0.167 & 0.23 \\
\hline Total insoluble & 12.61 & $1.81 \times 10^{-5}$ & $3.3 \times 10^{-6}$ & 0.44 & 0.242 & 0.182 \\
\hline Dissolved & 287.4 & $2.26 \times 10^{-5}$ & $1.05 \times 10^{-5}$ & 0.56 & 0.758 & 0.465 \\
\hline \multicolumn{7}{|l|}{ Sample 12-2 } \\
\hline Bulk rock & 300 & $4.07 \times 10^{-5}$ & $1.38 \times 10^{-5}$ & 1 & 1 & 0.34 \\
\hline Extracts & 0.02399 & $6.86 \times 10^{-6}$ & $6.89 \times 10^{-7}$ & 0.169 & 0.05 & 0.1 \\
\hline Residues & 13.05 & $6.46 \times 10^{-6}$ & $1.74 \times 10^{-6}$ & 0.159 & 0.126 & 0.269 \\
\hline Total insoluble & 13.07 & $1.33 \times 10^{-5}$ & $2.43 \times 10^{-6}$ & 0.328 & 0.176 & 0.183 \\
\hline Dissolved & 286.9 & $2.74 \times 10^{-5}$ & $1.137 \times 10^{-5}$ & 0.672 & 0.824 & 0.415 \\
\hline
\end{tabular}

rock's saturation remanent moment $\left(\mathrm{M}_{\mathrm{r}}\right)$. The significant loss of saturation moment is due to dissolution of magnetic particles by the acetic acid. Thus the magnetic extracts represent only a small portion of the magnetic particles in the bulk rock.

The different hysteresis ratios for the bulk rock, extract, and "nonmagnetic" residue suggest that the processes of dissolution and extraction each result in preferential loss of fine-grained magnetic carriers. Because of their greater surface area to volume ratio, fine particles are more susceptible to dissolution than coarser grains and are less efficiently recovered by magnetic extraction. However, the different hysteresis ratios of the bulk rock and extracts may also be attributable in part to increased magnetic interaction in the magnetic extraction. In order to verify the grain size difference suggested by hysteresis ratios, a series of low-temperature experiments were carried out.

No significant decrease was observed in room temperature NRM, ARM, or SIRM when the samples were cooled to liquid nitrogen temperature and warmed up through the Verwey phase transition in zero field. The intensities of NRM, ARM, and SIRM decrease $0.5 \%, 4 \%$, and $6 \%$, respectively, after lowtemperature treatment. This indicates that very little of the magnetic remanence is carried by true multidomain particles [Mauritsch and Turner, 1975; Lowrie and Heller, 1982; Dunlop and Argyle, 1989]. Figure 8 illustrates the behavior of lowtemperature saturation remanence during continuous thermal demagnetization. Samples were cooled to $2 \mathrm{~K}$ and saturated; the field was then reduced to zero, and the temperature was gradually increased by steps of $5 \mathrm{~K}$. The warming curves for bulk rock and extracts have somewhat different shapes. For the bulk rock, there is no obvious decrease around the Verwey transition. Half of the remanence is lost by $50 \mathrm{~K}$ and then there is a smooth decrease to room temperature, indicating that the remanence carriers are predominantly SP and SD magnetite particles. For the extracts, half of the remanence decrease happens before $100 \mathrm{~K}$, and around the Verwey transition, the remanence sharply decreases. This indicates that in relation to 


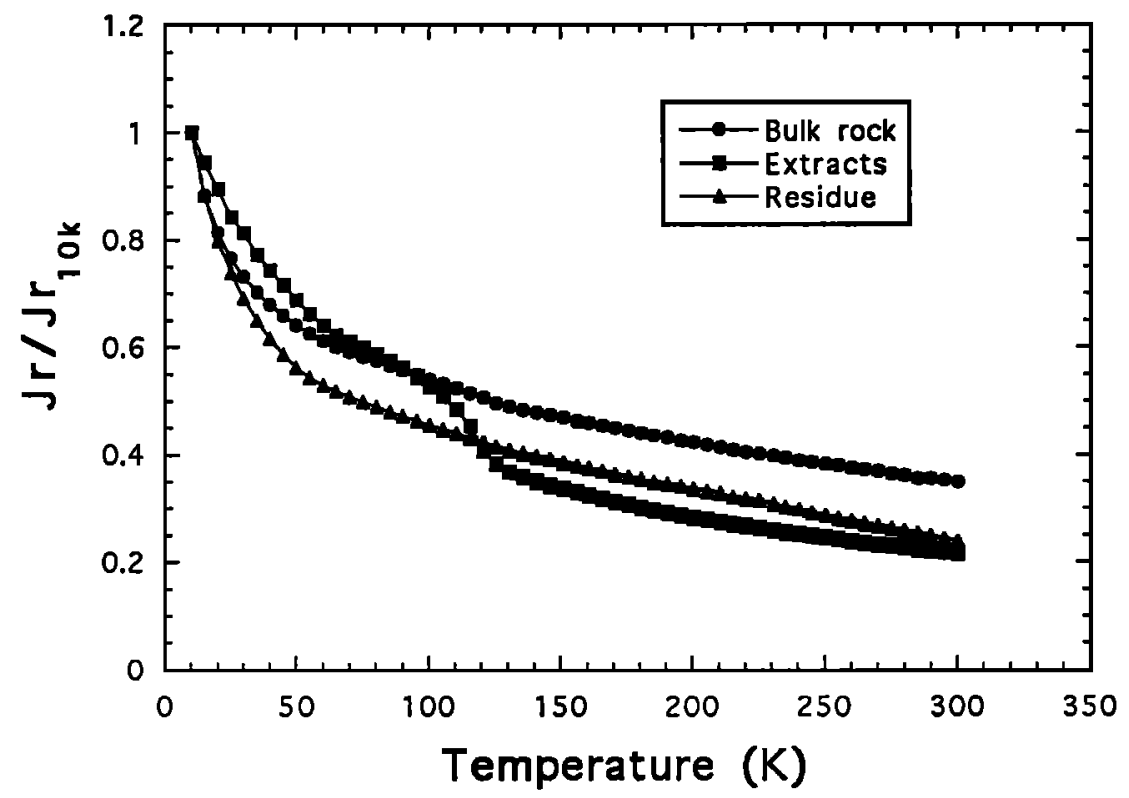

Flgure 8. Thermal demagnetization curves of low-temperature saturation remanence. There is no transition around the Verwey point for the bulk rock and "nonmagnetic" residue, but the extracts have an obvious transition at $120 \mathrm{~K}$.

the SP and SD content there are more MD magnetite particles in the extracts. For the "nonmagnetic" residue, the behavior is much like bulk rock's but with a somewhat higher SP/SD ratio.

\section{Discussion}

Approximately $60 \%$ of the saturation moment of our samples was lost during dissolution. The paramagnetically corrected $M_{s}$ values are directly proportional to magnetite content. Thus it is clear that during dissolution of the carbonate matrix, more than half of the magnetite was also destroyed. The extracts only contain $20 \%$ of the magnetite of the bulk rock; a comparable amount remains in the "nonmagnetic" residue. The fairly poor recovery rate suggests that the magnetic extracts may not be very representative of the bulk rock magnetite.

In fact, dissolution and extraction each clearly result in significant coarsening of magnetic grain size, as demonstrated by the different hysteresis behavior and different lowtemperature behavior of bulk rock, extracts, and "nonmagnetic" residue. This size differentiation can be reasonably attributed to preferential dissolution of finer grains and preferential extraction of larger ones.

For the extracts, thermal decay of the low-temperature remanence indicates the presence of significant fractions of SP, MD, and intermediate-sized particles. Hysteresis ratios suggest a mean particle size for the extracts in the coarse PSD range. SEM images show $10-\mu \mathrm{m}$ framboidal aggregates of micron-sized particles to be the most common form of magnetite present, and these framboids probably control the hysteresis properties of the extracts. Thus the strong differences between the properties of the extracts and those of the bulk rock indicate that the framboids make a fairly minor contribution to the magnetic behavior of whole rock samples.

Halgedahl and Suk [1992] studied hysteresis and alternating field response of large individual spheroids and framboids (tens to hundreds of microns) and concluded that they contribute very little to NRM. This is consistent with the observation of Saffer and McCabe [1992] that relative abundance of framboids is not strongly correlated with degree of remagnetization. The smaller spherical particles seen on the surfaces of some of the framboids (Figure 2b) are apparently quite similar to the equant $200 \mathrm{~nm}(0.2 \mu \mathrm{m})$ grains described by Suk et al. [1993] as volumetrically the most important magnetic material in their extracts from lower Paleozoic limestone of New York. Hysteresis measurements by Suk et al. [1993] on these fine particles, separated out of the extracts, yielded ratios very similar to those for the extracts of this study. They concluded that these abundant particles may be the principal carrier of NRM. However, in view of the bulk rock hysteresis properties and other evidence for a major population of finer, more efficient remanence carriers, it seems reasonable to suggest that the actual NRMbearing particles have not yet been observed petrographically.

The properties of the "nonmagnetic" residue are quite interesting. This residue has a total magnetite content comparable to that of the extracts and a saturation remanence greater by a factor of 2 . The $J_{r s} / J_{S}$ ratio thus indicates a significantly finer mean particle size than that of the extracts. Loops for the residue are strongly "wasp-waisted", and $\mathrm{H}_{\mathrm{cr}} / \mathrm{H}_{\mathrm{c}}$ ratios are very high. The two ratios appear to obey the same power-law relation observed in whole rock specimens of remagnetized carbonates [Jackson, 1990], with $\mathrm{J}_{\mathrm{rs}} / \mathrm{J}_{\mathrm{s}}=\mathbf{0 . 8 9}$ $\mathrm{H}_{\mathrm{cr}} / \mathrm{H}_{\mathbf{c}}{ }^{-1.6}$. Although this relation was initially interpreted in terms of a mixture of SD and coarser grains, more recent evidence for a large population of SP particles [Jackson et al., 1993] indicates that the wasp-waisted loops and high $\mathrm{H}_{\mathrm{cr}} / \mathrm{H}_{\mathrm{c}}$ values are probably controlled primarily by SP and SD grains, with larger particles making relatively minor contributions.

The characteristics of the magnetite lost to dissolution may be estimated by subtracting the $M_{T}$ and $M_{S}$ values for the extracts and "nonmagnetic" residues from those of the bulk rock (Table 1). This suggests that the dissolved magnetite was dominantly single-domain $\left(\mathrm{M}_{\mathrm{r}} / \mathrm{M}_{\mathrm{s}}\right.$ about 0.45$)$. 


\section{Conclusions}

Rock magnetism and scanning electron microscopy (SEM) observations document that the extracts only carry $20 \%$ of the saturation moment and $10 \%$ of the saturation remanence of the bulk rock. The framboids and individual small euhedral magnetic particles observed by SEM make a fairly minor contribution to the magnetic remanence of the remagnetized carbonates. The magnetic mineral of the remagnetized carbonates is dominated by single-domain and superparamagnetic magnetite which are lost during dissolution and separation procedures and which have not yet been observed petrographically.

Acknowledgments. This study was supported by NFS EAR $90-05075$ and 92-19616. We thank Chad McCabe and one anonymous reviewer for their constructive reviews. Institute for Rock Magnetism (IRM) contribution 9303. The IRM is funded by the Keck foundation, the National Science Foundation, and the University of Minnesota.

\section{References}

Bachtadse, V., R. Van der Voo, F. M. Haynes, and S. E. Kesler, Late Paleozoic magnetization of mineralized and unmineralized Ordovician carbonates from east Tennessee: Evidence for a post-ore chemical event, J. Geophys. Res., 92, 14,165-14,176, 1987.

Day, R., M. D. Fuller, and V. Schmidt, Hysteresis properties of titanomagnetites: Grain size and composition dependence, $P$ hys. Earth Planet. Inter., 13, 260-266, 1977.

Dunlop, D. J., and K. S. Argyle, Separating multidomain and singledomain-like remanences in PSD magnetites by low-temperature demagnetization, Eos Trans. AGU, 70, 1069, 1989.

Furuta, T., M. Otsuki, and T. Akimoto, Quantitative electron probe microanalysis of oxygen in titanomagnetites with implications for oxidation processes, J. Geophys. Res., 90, 3145-3150, 1985.

Halgedahl, S., and D. Suk, On the carriers of remanence in Paleozoic platform carbonates of North America, 2, Demagnetization characteristics of magnetite spherules vs. whole rock specimens from the Onondaga Formation, Eos Trans. AGU, 73 (43), Fall Meeting Suppl., 154, 1992.

Heam, P. P., Jr., J. F. Sutter, and H. E. Belkin, Authigenic K-feldspar: An indicator of the geochronology and chemical evolution of mineralizing fluids in sediment-hosted lead and zinc deposits (abstract), Proc. Int. Geol. Congr., 28, 246-247, 1989.

Jackson, M. J., Diagenetic sources of stable remanence in remagnetized Paleozoic cratonic carbonates: A rock magnetic study, J. Geophys. Res., 95, 2753-2761, 1990.

Jackson, M. J., W. W. Sun, and J. P. Craddock, The rock magnetic fingerprint of chemical remagnetization in midcontinental Paleozoic carbonates, Geophys. Res. Lett., 19, 781-784, 1992.

Jackson, M. J., P. Rochette, G. Fillion, S. K. Banerjee, and J. Marvin, Rock magnetism of remagnetized Paleozoic carbonates: Low-T behavior and susceptibility characteristics, J. Geophys. Res., 98, 6217-6225, 1993.

Lowrie, W., and F. Heller, Magnetic properties of marine limestones, Rev. Geophys., 20, 171-192, 1982.

Lu, G., S. Marshak, and D. V. Kent, Characteristics of magnetic carriers responsible for Late Palcozoic remagnetization in carbonate strata of the mid-continent, U.S.A., Earth Planet. Sci. Lett., 99, 351-361, 1990.

Lu, G., C. McCabe, J. S. Hanor, and R. E. Ferrell, A genetic link between remagnetization and potassium metasomatism in the Devonian Onondaga formation, northem Appalachian basin, Geophys. Res. Lett., 18, 2047-2050, 1991.

Mauritsch, H. J., and P. Tumer, The identification of magnetite in limestones using the low-temperature transition, Earth Planet. Sci. Lett., 24, 414-418, 1975.

McCabe, C., and R. D. Elmore, The occurrence and origin of late Paleozoic remagnetization in the sedimentary rocks of North American, Rev. Geophys., 27, 471-494, 1989.

McCabe, C., R. Van der Voo, D. R. Peacor, C. R. Scotese, and R. Freeman, Diagenetic magnetite carries ancient yet secondary remanence in some Paleozoic sedimentary carbonates, Geology, 11 . 221-223, 1983.

Saffer, B. and C. McCabe, Further studies of carbonate remagnetization in the northem Appalachian besin, J. Geophys. Res., 97, 4331-4348, 1992.

Schulze, D. G. and J. B. Dixon, High gradient magnetic separation of iron oxides and other magnetic minerals from soil clays. Soil Sci. Soc. Am. J., 43, 793-799, 1979.

Suk, D., and S. Halgedahl, On the carriers of remanence in Paleozoic platform carbonates of North America, 1, Hysteresis properties of individual magnetite spherules vs. whole rock specimens, EOS Trans. $A G U, 73$ (43), Fall meeting suppl., 153, 1992.

Suk, D., R. Van der Voo, and D. R. Peacor, Scanning and transmission electron microscope observations of magnetite and other iron phases in Ordovician carbonates from east Temnessee, J. Geophys. Res., 95. $12,327-12,336,1990 \mathrm{a}$.

Suk, D., D. R. Peacor, and R. Van der Voo, Replacement of pyrite framboids by magnetite in limestone and implication for paleomagnetism, Nature, 345, 611-613, $1990 \mathrm{~b}$.

Suk, D., R. Van der Voo, and D. R. Peacor, Origin of magnetite responsible for remagnetization in early Paleozoic limestones of New York State, J. Geophys. Res., 98, 419-434, 1993.

Sun, W. W., M. Jackson, and J. P. Craddock, Relationship between remagnetization, magnetic fabric, and deformation in the midcontinental Paleozoic carbonates, Tectonophysics, 221, 361-366, 1993.

Van der Voo, R. , Phanerozoic paleomagnetic poles from Europe and North America and comparisons with continental reconstructions, Rev. Geophys., 28, 167-206., 1990.

M. Jackson and W. Sun, Institute for Rock Magnetism, Department of Geology and Geophysics, 100 Union Street SE, Minneapolis, MN 554550128. (e-mail: sunxx001@maroon.tc.umn.edu)

(Received March 5, 1993; revised August 18, 1993; accepted September 28, 1993.) 